\title{
Persistence and Cure Rates of Primary Hyperparathyroid Disease after Bilateral Neck Exploration (BNE)
}

\author{
Authors \\ Mohamed Zaky Azzam ${ }^{1}$, Eman Zaki Azzam ${ }^{2}$, Tarek Youssef Koraitum ${ }^{1}$ \\ ${ }^{1}$ Department of General Surgery (Head, Neck \& Endocrine Unit) Alexandria University, Egypt \\ ${ }^{2}$ Departement of Internal Medicine (Endocrine Unit) Alexandria University, Egypt \\ Corresponding Author \\ Eman Zaki Azzam \\ Department of Internal Medicine (Endocrine Unit) \\ University of Alexandria, Egypt \\ Phone:+201060882079, fax: 002034862506 \\ Email: azzam_eman@yahoo.com
}

\begin{abstract}
Eighteen patients suffering from primary hyperparathyroid (PHPT) disease underwent BNE in Alexandria University Hospital in the last two years with the objective to estimate the accuracy of imaging in localizing the site of the disease and the efficacy of BNE in cure rates in these patients. Single gland disease (SGD) was found in 13 patients (72\%) and multigland disease (MGD) in 5 patients (28\%). In the 13 patients with SGD, the disease was confined to one of the lower parathyroid glands (5 in the right gland and 8 in the left one). During the period of regular postoperative follow up for six months, 15 patients achieved complete cure (83\%) and 3 patients (17\%) showed persistence of the disease. These three patients were having SGD; one of them the cause of persistence was carcinoma of the excised PT gland while in the other two the cause of persistence was activation of an occult adenoma in the other neighboring lower PT gland.
\end{abstract}

Keywords: PHPT, BNE, PTH, SGD, MGD.

\section{Introduction}

PHPT is a disease characterized by inappropriate secretion of parathyroid hormone (PTH) with respect to the extracellular calcium concentration ${ }^{(1)}$. PHPT is most often caused by benign neoplastic proliferation taking place in one parathyroid (PT) gland as an adenoma. It may also be caused by benign neoplastic proliferation taking place in all four PT glands as MGD or primary hyperplasia. Rarely it is caused by malignant neoplastic proliferation taking place in one of the PT glands as carcinoma ${ }^{(2)}$. Neoplastic PT disease may occur in association with neoplastic proliferation taking place in other endocrine glands as Multiple Endocrine Neoplastic Syndromes (MEN) I and II ${ }^{(3)}$. 
PHPT disease is characterized by continuous loss of calcium from the skeleton and hypercalcaemia. Prolonged hypercalcaemia is associated with ectopic calcification of blood vessels especially the media of arteries with increased incidence of arterial hypertension, cardiac arrhythmias and strokes ${ }^{(4)}$. Ectopic calcification occurs also in the kidneys resulting in nephrocalcinosis with progressive deterioration in kidney function and ultimate renal failure. Continuous filtering of calcium through the kidneys results in formation of renal stones and urinary tract infection ${ }^{(5)}$. Severe hypercalcaemia $(>14 \mathrm{mg} \%)$ is responsible for hypercalcaemic crisis which is characterized by severe vomiting, dehydration and if untreated it may lead to oliguric renal failure, bradycardia with complete heart block, stupor and coma ${ }^{(6)}$. Prolonged loss of calcium from the skeleton results in osteoporosis, deformities of the spine, cystic tumors of bone (osteitis fibrosa cystica), brown tumors of the jaw and pathological fractures ${ }^{(7)}$.

The typical patient of PHPT has had his disease for several years before it is ever found. Most patients are discovered as asymptomatic hypercalcaemia during routine measurement of serum calcium in hospitalized patients or in evaluation of postmenopausal women suffering from osteoporosis in whom hypercalcaemia was found to be associated with elevated PTH. In countries where routine measurements of serum calcium is not practiced in hospitalized patients, the disease presents by skeletal and urinary tract complications ${ }^{(8)}$.

Since 1925, BNE has been the standard surgical treatment of PHPT. The operation entails surgical removal of PT gland (s) which are overproducing PTH and leaving the normal one(s) ${ }^{(9)}$. In the last 10 years refinement in imaging techniques to localize the disease include allowed for preoperative identification of all hyperfunctioning PT glands and development of new surgical techniques for parathyroidectomy (PTX) ${ }^{(10)}$. Unilateral approach to PTX on the side showing the enlarged gland associated with intraoperative parathyroid hormone assay(IOPTH); a decrease of more than 50\% from the preoperative level at 5-10 minutes following resection suggest that the patient will be cured. If this drop did not occur, then MGD is suspected and BNE becomes necessary. When all patients who were operated upon on one gland were followed; a lot of these patients come back and have a second operation because they have a second tumor. Therefore the concept of unilateral exploration based on positive scan and IOPTH assay was found to be limited by the presence of MGD combined with imperfection in preoperative localizing technique. Therefore PTX with less than four gland exploration did not gain wide acceptance ${ }^{(11)}$.

\section{Methodology}

Eighteen patients suffering from PHPT disease were examined clinically and evaluated biochemically. Preoperative ultrasound (US) using $10 \mathrm{mHz}$ transducer was done to localize the disease in the neck. In addition, technetium 99 (Tc-99) sestamibi scan was done sequentially following intravenous administration of 20 millicurie with an early image (20 minutes) and after 3 hours postinjection to detect diseased gland(s) in ectopic locations in the neck and mediastinum.

BNE was performed for all patients regardless the results obtained by imaging to assess the degree of perfection of imaging in localizing the disease. The operation allows for exposure of all PT glands through a collar incision in the neck like that used for thyroidectomy. PT glands were evaluated and the diseased gland(s) were excised.

Patients were followed up postoperatively by assessing PTH level immediately, at 3 months and at 6months after operation. The patient was considered cured if the level of PTH reached the normal range and maintained during the period of follow up. The disease is considered persistent if the level of PTH did not attain the normal level or begins to rise after initial drop. 


\section{Results:}

\section{I-Clinical results}

1-Age:

Table (1) shows the age groups of patients.

\begin{tabular}{|l|l|l|}
\hline Age group & Number & Percent \\
\hline $20-29$ & 1 & 5.5 \\
\hline $30-39$ & 1 & 5.5 \\
\hline $40-49$ & 2 & 11 \\
\hline $50-59$ & 10 & 55.5 \\
\hline $60-69$ & 3 & 17 \\
\hline $70-79$ & 1 & 5.5 \\
\hline Total & 18 & 100 \\
\hline
\end{tabular}

\section{2-Gender:}

Table (2) shows the gender of patients.

\begin{tabular}{|l|c|c|}
\hline \multirow{2}{*}{ Age group } & \multicolumn{2}{|c|}{ gender } \\
\cline { 2 - 3 } & male & female \\
\hline $20-29$ & 0 & 1 \\
\hline $30-39$ & 0 & 1 \\
\hline $40-49$ & 1 & 1 \\
\hline $50-59$ & 4 & 6 \\
\hline $60-69$ & 1 & 2 \\
\hline $70-79$ & 1 & 0 \\
\hline total & 7 & 11 \\
\hline
\end{tabular}

\section{3- Presentations:}

Table (3) shows patients' presentations.

\begin{tabular}{|l|l|l|}
\hline Presentations & Number & Percent \\
\hline Incidental biochemical discovery & 1 & 5.5 \\
\hline Skeletal complication & 14 & 78 \\
\hline Renal complications & 11 & 61 \\
\hline Concurrent skeletal and renal complications & 8 & 44 \\
\hline
\end{tabular}

\section{4-Comorbidities:}

Table (4) shows patients' Comorbidities.

\begin{tabular}{|l|l|l|}
\hline Comorbidity & Number & Percent \\
\hline Hypertension & 14 & 78 \\
\hline Short Q-T interval in ECG & 6 & 33 \\
\hline Diabetes mellitus & 4 & 22 \\
\hline Peptic ulcer & 1 & 5.5 \\
\hline
\end{tabular}

\section{II-Biochemical results}

Table (5) shows the biochemical results of patients.

\begin{tabular}{|l|l|l|l|}
\hline & Range & Mean & $\begin{array}{l}\text { Standard } \\
\text { deviation }\end{array}$ \\
\hline Parathormone (15-65 pg/ml) & $313-2000$ & 1179.72 & 491 \\
\hline Calcium (9-10 $\mathrm{mg} \%)$ & $11-14.8$ & 12.22 & 1 \\
\hline Bone alkaline phosphatase (25-90 U/l) & $250-1100$ & 641.2 & 211 \\
\hline
\end{tabular}




\section{III-Imaging results}

1-Ultrasound of the neck

Table (6) shows the results obtained by US scan of the neck in patients.

\begin{tabular}{|l|c|c|}
\hline Anatomical site & Number & Percent \\
\hline Right upper PT gland & 0 & 0 \\
\hline Left upper PT gland & 0 & 0 \\
\hline Right lower PT gland & 5 & 28 \\
\hline Left lower PT gland & 9 & 50 \\
\hline Negative & 4 & 22 \\
\hline Total & 18 & 100 \\
\hline
\end{tabular}

2-Sestamibi scan of the neck and mediastinum

Table (7) shows results obtained by sestamibi scan of the neck and mediastinum.

\begin{tabular}{|l|c|c|}
\hline Anatomical site & Number & Percent \\
\hline Right upper PT gland & 0 & 0 \\
\hline Left upper PT gland & 0 & 0 \\
\hline Right lower PT gland & 5 & 28 \\
\hline Left lower PT gland & 9 & 50 \\
\hline Ectopic & 0 & 0 \\
\hline Negative & 4 & 22 \\
\hline Total & 18 & 100 \\
\hline
\end{tabular}

IV-Surgical results:

Table (8) shows the results of BNE as compared with the results obtained by imaging.

\begin{tabular}{|l|c|c|c|}
\hline Diagnosis & BNE & Positive scan & Sensitivity $\%$ \\
\hline SGD & 13 & 13 & 100 \\
\hline MGD & 5 & 1 & 20 \\
\hline Total & 18 & 14 & 78 \\
\hline
\end{tabular}

\section{V- Follow up results}

Table (8) shows the results of histopathological diagnosis and its relation to persistence and cure rates of patients .

\begin{tabular}{|l|c|c|c|}
\hline Pathological diagnosis & Number & Cure & Persistence \\
\hline SGD (Adenoma) & 12 & 10 & 2 \\
\hline SGD (Carcinoma ) & 1 & 0 & 1 \\
\hline Hyperplasia & 5 & 5 & 0 \\
\hline Total & 18 & 15 & 3 \\
\hline
\end{tabular}

Table (9) shows the results of pre and postoperative PTH assay in cured patients.

\begin{tabular}{|l|c|c|c|c|c|}
\hline \multirow{2}{*}{ Diagnosis } & Number of & \multicolumn{5}{|c|}{ Mean PTH level (pg/ml) } \\
\cline { 3 - 6 } & patients & Preoperative & $\begin{array}{c}\text { Immediate } \\
\text { postoperative }\end{array}$ & $\begin{array}{c}\text { At 3 months } \\
\text { Postoperative }\end{array}$ & $\begin{array}{c}\text { At 6 months } \\
\text { postoperative }\end{array}$ \\
\hline Adenomas & 10 & 1088 & 110 & 85 & 71 \\
\hline MGD & 5 & 1542 & 195.7 & 85.4 & 74 \\
\hline
\end{tabular}

Table (10) shows PTH pre and postoperative in the 3 patients with persistent disease

\begin{tabular}{|l|l|l|l|l|}
\hline \multirow{2}{*}{ Diagnosis } & \multicolumn{3}{|l|}{ Mean PTH level (pg/ml) } \\
\cline { 2 - 5 } & Preoperative & $\begin{array}{l}\text { Immediate } \\
\text { postoperative }\end{array}$ & $\begin{array}{l}\text { At 3 months } \\
\text { Postoperative }\end{array}$ & $\begin{array}{l}\text { At 6 months } \\
\text { postoperative }\end{array}$ \\
\hline Carcinoma & 1500 & 300 & 1000 & 1300 \\
\hline Adenoma in $1^{\text {st }}$ patient & 1300 & 220 & 500 & 950 \\
\hline Adenoma in $2^{\text {nd }}$ patient & 1000 & 180 & 480 & 600 \\
\hline
\end{tabular}




\section{Discussion}

The clinical results showed that the peak incidence of the disease occurs in the sixth decade of life. This was found to be in accord with the incidence of the disease worldwide ${ }^{(12)}$. The number of affected females outnumbered that of males; the ratio being 1.5:1. This was found also to be in accord with what was found worldwide ${ }^{(13)}$. The disease was symptomatic in $94.5 \%$ of patients, being incidentally discovered in only one patient $(5.5 \%)$. Seventy eight percent of patients had already skeletal complications in the form of osteoporosis affecting the compact bone of the skeleton and could be demonstrated in the plain x-rays of the skull, the region of the wrist and the spine. One of the affected patients showed cystic bone destruction associated with pathological fracture of the tibia. Another patient was found to have brown tumor of the mandible. It is well known that osteoporosis cannot be diagnosed by plain x-ray except after there have been more than $40 \%$ loss of bone mass of the skeleton ${ }^{(14)}$.In addition US of the kidneys showed that there are $61 \%$ of patients who had already renal stones. Nephrocalcinosis was demonstrated in one of these patients. Concurrent skeletal and renal complications were found in $44 \%$ of patients. This way in discovery of the disease was also found in other countries including India ${ }^{(15)}$, Pakistan ${ }^{(16)}$, Turkey ${ }^{(17)}$ and Iran ${ }^{(18)}$.

The presentation and discovery of PHPT disease in the present study was quite different from the presentation and discovery of the disease in developed countries. In the USA study, $80 \%$ of the diseased patients are picked up incidentally through routine finding of persistent hypercalcaemia in hospitalized population. Only 5\% had skeletal symptoms and $15 \%$ had renal symptoms. Concurrent skeletal and kidney affection was not recorded ${ }^{(19)}$. This way of discovery of PHPT disease was also found in other countries including South Africa ${ }^{(20)}$ and Hong Kong ${ }^{(21)}$.

Physical examination of patients revealed the presence of hypertension in $78 \%$ of patients while its incidence worldwide ranged between $10-40 \%{ }^{(22)}$. After PTX hypertension is either cured or becomes controllable ${ }^{(23)}$. ECG changes in the form of short QT interval were present in $33 \%$ of patients. The importance of this finding is its association with ventricular premature beats (VPBs). PTX eliminates the arrhythmic risk of VPBs ${ }^{(24)}$. Diabetes mellitus was found in $22 \%$ of patients, similar studies reported higher rates of type 2 diabetes in association with PHPT disease. Previous reports have suggested that control of diabetes improves after PTX ${ }^{(25)}$. Contrary to what was published in old articles which list peptic ulcer and pancreatitis to be famous symptoms ${ }^{(26)}$, only one case of peptic ulcer and no case of pancreatitis were found in the present study.

Biochemical diagnosis of PHPT disease is established in the presence of high PTH levels $>65 \mathrm{pg} / \mathrm{ml}$ associated with hypercalcaemia $>10 \mathrm{mg} \%{ }^{(19)}$. Patients in this study were characterized by very high levels of PTH with a mean value of $1179 \pm 491 \mathrm{pg} / \mathrm{ml}$ which is about 30 times more than the normal level while the mean value of PTH in patients in USA study had a PTH level $\leq 250 \mathrm{pg} / \mathrm{ml}$ which is only about four times the normal level ${ }^{(27)}$.It was found that there is a relation between PTH level and the size and duration of the PT lesion ${ }^{(19)}$. Also the patients in this study were characterized by high calcium levels with mean value 12.2 $\pm 1.0 \mathrm{mg} \%$ which is much higher than that obtained with patients with PHPT disease in USA study who had calcium levels with mean value of $10.8 \mathrm{mg} \%$ and no single case had levels above $11.5 \mathrm{mg} \%{ }^{(27)}$. It was found that there is a relation between calcium level and the severity of symptoms in PHPT disease ${ }^{(19)}$. Also our patients are characterized by having high levels of serum bone alkaline phosphatase (ALP) with mean value $641 \pm 211 \mathrm{U} / 1$ which is about 10 times the normal level. In contrast, patients with PHPT in USA study had either normal or slightly elevated ALP. High levels of ALP reflect the severity of PTH on the skeleton and the degree of bone turnover and denote that the degree of bone resorption and bone formation is maximum in our patients and minimum in asymptomatic patients in USA study ${ }^{(27)}$.

At present, in many centers, all patients having PHPT disease undergo routine preoperative US of the neck to localize the site of the diseased gland(s) being most cost effective procedure, painless, non invasive and 
does not expose the patient to radiation. However its accuracy is highly operator dependant and has poor sensitivity in detecting glands in ectopic locations due to acoustic shadows from overlying bone or air ${ }^{(28)}$. All patients in this study underwent US scanning to localize the diseased PT glands. It was positive in detecting the disease in 78\% of patients; all were present in the lower two glands ( 5 in the right, 9 in the left). In addition sestamibi scan was done to all patients in order to localize the disease in its entopic as well as ectopic locations. It was positive in localizing the disease in $78 \%$ of cases; all were in the lower glands with no single patient showing the disease in any ectopic location. The major factors contributing to non localizing of sestamibi are small glands $(<1.5 \mathrm{~cm})$, MGD, and double adenomas ${ }^{(29)}$.

BNE which has been evolved as the gold standard for surgical treatment of PHPT disease was used to estimate the sensitivity of imaging in PHPT disease ${ }^{(30)}$. The operation was done to all patients regardless the results of localization obtained by imaging. SGD was found in 13 patients (72\%); 5 in the right lower gland and 8 in the left lower gland. All were localized preoperatively by both US and sestamibi scans giving $100 \%$ sensitivity in the diagnosis of SGD. The excised glands were bean size, olive size and lemon size reflecting the long duration of the disease. MGD affecting all the four glands was found in 5 patients (28\%) in whom three and half glands were excised leaving half of the left upper PT gland intact to carry the function of PTH secretion. Both US and sestamibi scans were able to localize MGD in only one patient (20\% sensitivity) and localizing the disease in only one of the lower PT glands.

The efficacy of BNE on the cure rate of patients with PHPT disease was assessed by PTH assay during the period of follow up (immediately after surgery, at 3 months and at 6months). Biochemical cure was achieved in 10 out of the 13 patients with SGD (77\% cure rate) and in all 5 patients of MGD was $100 \%$ cure rate. In the cured patients with SGD there was an immediate drop of PTH level postoperatively from the mean value of $1088 \mathrm{pg} / \mathrm{ml}$ to mean value of $110 \mathrm{pg} / \mathrm{ml}$ (90\% drop) and subsequent slow drop to reach the level of $85 \mathrm{pg} / \mathrm{ml}$ after 3 months and the level of $71 \mathrm{pg} / \mathrm{ml}$ after 6 months. In the 5 patients with cured MGD, there was an immediate drop of PTH from the mean value of $1542 \mathrm{pg} / \mathrm{ml}$ to reach the mean level of $195.7 \mathrm{pg} / \mathrm{ml}$ (94\% drop) with gradual slow drop after 3 months to reach a mean value of $85.4 \mathrm{pg} / \mathrm{ml}$ and 74 $\mathrm{pg} / \mathrm{ml}$ after 6 months.

Postoperative follow up showed persistence of the disease in 3 out of 13 patients of SGD (23\%). In one of the patients, the excised gland proved histopathologically to be carcinoma in the right lower gland. Biochemical follow up of this patient showed immediate drop of PTH level from preoperative value of 1500 $\mathrm{pg} / \mathrm{ml}$ to reach a level of $300 \mathrm{pg} / \mathrm{ml}$ (80\% drop). The level began to increase to reach $1000 \mathrm{pg} / \mathrm{ml}$ after 3 months and to $1300 \mathrm{pg} / \mathrm{ml}$ after 6 months. Both US and sestamibi scan of this patient showed persistence of the disease in the same site due to inadequate resection of the gland. In the other two patients in whom the excised glands were adenomas, biochemical follow up in one of them showed an immediate drop of PTH level from preoperative value of $1300 \mathrm{pg} / \mathrm{ml}$ to $220 \mathrm{pg} / \mathrm{ml}(83 \%$ drop), PTH level began to rise to $500 \mathrm{pg} / \mathrm{ml}$ after 3 months and to $950 \mathrm{pg} / \mathrm{ml}$ after 6 months. The other patient showed immediate drop from 1000pg/ml to $180 \mathrm{pg} / \mathrm{ml}$ (82\% drop) then the level began to increase to the level of $480 \mathrm{pg} / \mathrm{ml}$ after 3 months and 600 $\mathrm{pg} / \mathrm{ml}$ after 6 months. Both US and sestamibi scans showed that the persistence of the disease was due to the presence of a second adenoma in the neighboring lower gland which appeared normal in the initial surgery.

Carcinoma of the PT gland is a common cause of persistence of PHPT disease after initial surgery ${ }^{(31)}$. Given the rarity of this neoplasm and the surgeon expectation of the disease being PT adenoma for which simple gland removal is appropriate, a high rate of local persistence of the disease may occur. Even at expert institution with experienced PT surgeons up to $86 \%$ of cases of PT carcinoma have not been appreciated initially by the surgeon ${ }^{(32)}$. Another common cause of persistence of PHPT disease is the presence of an occult adenoma in the neighboring lower PT gland which appears normal even to most experienced surgeons in the initial surgery ${ }^{(33)}$. 


\section{Conclusion}

Imaging of PT glands serves in localizing PHPT disease in entopic as well as ectopic locations but should not direct the surgical procedure because when negative, BNE becomes a must to explore the four glands and deal with the disease. When it is positive it shows only one gland which may be an adenoma, carcinoma or hyperplasic gland, BNE is still a must because the surgical procedure is different in each disease.

Although BNE is considered the gold standard to deal with PHPT worldwide, yet it cannot guarantee cure in SGD even at expert institutions with most experienced surgeons.

\section{Reference}

1. Delellis RA. Tumors of the parathyroid gland. In: Atlas of tumor pathology. Third series. Fascicle 6. Washington. DC: Armed Forces Institute of Pathology: 1993: 25-51. 65-78.

2. Roth SI, Flame JB. Tumors of the parathyroid glands. Second series, Fascicle 14. Atlas of tumor pathology. Washington DC: Armed Forces Institute of Pathology: 1978: 74-82.

3. Thakker RV. "Multiple endocrine neoplasia-syndromes of the twentieth century." J Clin Endocrinol Metabol 1998; 83 (8): 2617-20.

4. Walker MD, Tullio MR. "Cardiovascular aspect of primary hyperparathyroidism. J Endocrinol Invest 2008; 31: 925-31.

5. Sun JM, Cronan JJ, Monchik JM. Primary hyperparathyroidism and increased prevalence of renal stone disease. Am J Roentgenol 2008; 191: 908-11.

6. Bargren AE, Repplinger D, Chen SR. "Can biochemical abnormalities predict symptomatology in patients with primary hyper-parathyroidism?" J Am Coll Surg 2011; 212 (3):410-4.

7. Khan J, Bilezikian JP, Potts JT. "The diagnosis and management of asymptomatic primary hyperparathyroidism revisited". J Clin Endocrinol Metab 2009; 94(2): 334.

8. Lewiecki EM, Mosekilde I, Rubin MR. "Primary hyper-parathyroidism: Proceedings of Third International Workshop". J Clin Endocrinol Metab 2009; 94: 351-65.

9. Mandl F. Therapeutischer versuch bei ostitis fibrosa generalisata Mittles. Exstripationeines epithelkör-perlichen Tumors when klin Wochensher. 1925; 50: 1343.

10. Norman J. Controversis in Parathyroid surgery. The quest for a "mini" unilateral parathyroid operation seem to gone too far. J Surg Oncol 2012; 105 (1): 1-3.

11. Sackett WR, Barraclough B, Reeve TS, Delbridge LW. "Worldwide Trends in the Surgical Treatment of Primary Hyperparathyroidism in the Era of Minimally Invasive Parathyroidectomy. Arch Surg 2002; 137 (9): 1055-9.

12. Clark OH. Diagnosis of primary hyperparathyroidism. In: Clark OH, Duh G-Y, eds. Textbook of endocrine surgery. Philadelphia: Saunders 1997; 297-301.

13. Wermers RA, Khosla S, Atkinson EJ, Achenbach SJ, Oberg AL, Grant CS, Melton 3rd LJ. Incidence of primary hyperparathyroidism in Rochester, Minnesota, 1993-2001: an Update on the changing epidemiology of the disease. J Bone Miner Res 2006; 21: 171-7.

14. Kanis JA. Diagnosis of osteoporosis. The lancet 2002; 359(9321): 1929-36.

15. Pradeep PV, Jayashree B, Anjali M, Mishra SK. Systematic review of primary hyperparathyroidism in India. Int J Endocrinol 2011; 92: 814-7.

16. Biyabani R, Talati J. Primary hyperparathyroidism in Pakistan, The pattern of the disease is different from the west. Journal of The Pakistan Medical Association 1999; 49(8): 194-9.

17. Uhluhizarci K, Cloak M, Kula Evaluation of sixteen patients with primary hyperparathyroidism. Turkish Journal of Endocrinology and Metabolism 2000; 4: 139-42. 
18. Hamidi S, Soltani A, Hedayat P, Kamalian N. Priamry hyperparathyroidism: a review of 177 cases. Medical Science Monitor 2006; 12: 86-9.

19. Norman J, Goodman A. Calcium, parathyroid hormone and vitamin D in patients with primary hyperparathyroidism: normograms developed from 10.000 cases. Endocr Pract 2010; 6: 1-26.

20. Diamond HT, Botha WJ, Kalk J, Shires R. Primary hyperparathyroidism. A study of 100 patients in Johannesburg. South African Med J 1986; 69: 94-7.

21. Loo YC, Kung W, Lam S. Surgical treatment for primary hyperparathyroidism. Chin Med J 1997; 110: 612-6.

22. Dluhy RG. Uncommon forms of secondary hypertension. Am J Hypertension 1998; 11: 528-69.

23. Luimachi F, Ermani M, Luisetto G, Nardi A, Camozzi V, Favia G. Relationship between serum parathyroid hormone, serum calcium and arterial blood pressure in patients with primary hyperparathyroidism. Europ J Endocrinol 2002; 146: 643-57.

24. Jesica P, Mario C, Sergio M, Marisa V, Mirella C. Parathyroidectomy eliminates arrhythmic risk in primary hyperparathyroidism, as evaluated by exercise test. Europ J Endocrinol 2013; 169: 255-61.

25. Cardenas M, Vigil K, Talpos GB, Lee MW. Prevalence of type 2 diabetes mellitus in patients with primary hyperparathyrodism. Endocr Pract 2008; 14: 69-75.

26. Bess MA, Edis AJ, Van Heerden J. Hyperparathyroidism and pancreatitis: chance or a causal association?. JAMA 1980; 243:246-9.

27. Norman J. Primary hyperparathyroidism a study of 15.000 case. Am Coll Surg 2011; 16: 1: 12.

28. Sargiotto A, D'Amelio P. Preoperative localization of parathyroid adenoma with sonogrpahy in primary hyperparathyroidism. J Clin Ultrasound 2007; 35: 186-90.

29. Jones JM, Russell C, Ferguson W. Preoperative sestamibi-technetium scintigraphy in primary hyperparathyroidism: experience with 156 consecutive patients. Clin Radiol 2001; 56: 556-9.

30. Tibblin S, Bondesson A, Uden P. Current trends in the surgical treatment of solitary parathyroid adenoma. A questionnaire study form 53 surgical departments in 14 countries. Eur J Surg 1991; 157: 103-7.

31. Sandelin K, Auer G, Bondeson L, Grimelius L. Prognosis of parathyroid carcinoma: a review of 95 cases. World J Surg 1992; 16: 724-31.

32. Sandelin K, Tullgren O, Farnebo L. Evaluation and surgical management of malignant parathyroid disease. World J Surg 1999; 23: 68-74.

33. Mate D, Eugene M, Charles H, Quan Y, Siperstein M, Orlo H. Reoperation for persistent or recurrent primary hyperparathyroidism. Arch Surg 2004; 152: 1261-9. 